\title{
Retratos da saúde pública: o caos como intencionalidade nas fotografias do jornal Folha de Londrina
}

\author{
Reinaldo César Zanardi \\ Universidade Estadual de Londrina - rczanardi@gmail.com \\ Mestrando em Comunicação da UEL. Professor da Universidade Norte do Paraná (Unopar).
}

Paulo César Boni

Universidade Estadual de Londrina - pcboni@sercomtel.com.br Doutor em Ciências da Comunicação pela Universidade de São Paulo (USP). Coordenador do Mestrado em

Comunicação da Universidade Estadual de Londrina (UEL)

\begin{abstract}
Resumo
A mensagem de uma fotografia não passa despercebida, podendo gerar significados diversos. 0 objetivo deste trabalho é analisar dez fotografias que retratam a crise na saúde pública de Londrina, estado do Paraná, em reportagens do jornal Folha de Londrina, entre fevereiro e março de 2011. A saúde no município, desde o início do atual governo municipal, passou por várias crises que afetaram diretamente os serviços assistenciais à população, de falta de médicos a superlotação dos hospitais, passando pela interrupção do atendimento dos prontossocorros. Em menos de 24 meses, a Secretaria Municipal de Saúde teve cinco titulares. Esse estudo adota como metodologia a desconstrução analítica para aferição da intencionalidade da comunicação, proposta por Boni (2000). Como resultado, pode-se afirmar que os fotógrafos tomaram as imagens que retratam o tema dando-lhe significados como crise, falência e caos na saúde pública de Londrina.
\end{abstract}

\section{Palavras-chave}

Fotojornalismo; Folha de Londrina; Saúde pública de Londrina (PR); Geração de sentido.

\begin{abstract}
The message of a photograph is not lost and can create different meanings. The aim of this paper is to examine ten photographs depicting the crisis in public health in Londrina, state of Paraná, in reports of the newspaper Folha de Londrina, in February and March 2011. Health in the city since the beginning of the current city government, has gone through many crises affecting directly the public health services to the population, since shortage of doctors, overcrowded hospitals until the interruption of service of emergency rooms. In less than 24 months, the City Department of Health has had five chefs. This study is the intentionality of communication methodology proposed by Boni (2000). As a result, can be said that the photographers took images that portray the theme giving it meaning as a crisis, bankruptcy and chaos in public health in Londrina.
\end{abstract}

\section{Keywords}

Photojournalism; Folha de Londrina; Londrina (PR) public health; Meaning generation. 


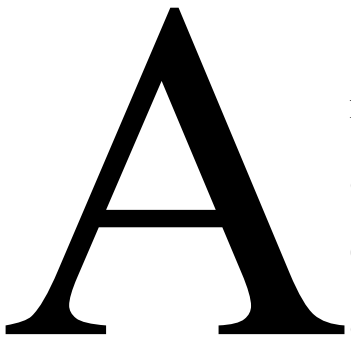

fotografia atende a diversos interesses, da divulgação de fatos ao registro da história; da visibilidade de ações pessoais e/ou coletivas à representação da realidade; do choque por seu conteúdo à conscientização por sua mensagem. O fato é que a fotografia assumiu um status que seus criadores no século XIX não imaginavam que ela atingisse no mundo atual.

Em estudos sobre fotojornalismo, da estética da composição imagética à pesquisa sobre a influência da imagem no processo social, fica evidente que a fotografia tem uma capacidade intrínseca de gerar sentidos, de criar significados, de comunicar algo ao espectador.

A mensagem imagética não passa despercebida, podendo criar sensações diversas, que vão da indiferença à comoção; da indignação à repugnância; do tanto faz à mobilização. A capacidade de construir significados da fotografia não é aleatória e conta com vários suportes como a visão do repórter fotográfico, a linha editorial do veículo, a ação dos profissionais da redação e os recursos tecnológicos disponíveis para sua produção e pós-produção.

Neste contexto, estudar a fotografia e seus significados é levantar informações por trás da composição imagética; é desvendar os sentidos nela inscritos e decifrar os códigos que revelam também a intencionalidade de quem a produz. Enquadramento, movimento, perspectiva, profundidade, foco, textura, ângulo, contraste e luz são mais do que elementos da linguagem fotográfica; são elementos que - combinados intencionalmente - transmitem informações e constroem significados, sejam poéticos, políticos, sociais ou ideológicos.

Neste sentido, o objetivo deste trabalho é analisar fotografias do jornal Folha de Londrina, nos meses de fevereiro e março de 2011, que retratam a crise na assistência à saúde pública no município de Londrina. Este estudo justifica-se pela necessidade de compreender o tratamento dado ao tema pelo referido diário, o mais antigo em circulação no norte do Paraná, e os sentidos gerados pela composição das fotografias num tema que mexe com toda a sociedade. Afinal, a área de saúde lida com elementos que se complementam e, ao mesmo tempo, se contrapõem como doença e saúde, vida e morte.

Este estudo adota como metodologia a desconstrução analítica da imagem, proposta por Boni (2000). Por este método é possível, com base no conceito de cada 
Estudos em Jornalismo e Mídia - Vol. 9 № 2 - Julho e Dezembro de 2012

elemento desconstruído, seja dos recursos técnicos (lentes, filtros e outros acessórios) ou da linguagem fotográfica utilizada (plano, ângulo, foco e outros), aferir a intencionalidade de comunicação de quem tomou a imagem ou do veículo que a publicou. $\mathrm{O}$ pesquisador afirma que há muitas maneiras de o fotógrafo manifestar sua intencionalidade. "Existem formas de se escrever em fotografia, mesmo sabendo que os códigos abertos e contínuos que compõem a mensagem não direcionam completamente a leitura." (BONI, 2000, p. 14). De acordo com Boni, a intencionalidade é natural ao trabalho do repórter fotográfico que tem como função primária informar os leitores do veículo no qual atua. Ele defende que a imagem produzida pelo profissional consiste em uma notícia.

Uma fotografia sua, para o veículo e para os leitores, é notícia tanto quanto o texto do repórter que cobriu a ocorrência. Assim, ao fotografar, ele sabe estar escrevendo com imagens da mesma forma que o repórter escreve com palavras (BONI, 2000, p. 200).

A intencionalidade dos fotógrafos do jornal Folha de Londrina, na cobertura da crise na assistência à saúde no município, será levantada a partir dos elementos da linguagem fotográfica das imagens publicadas. Assim, será analisado o conteúdo informativo inscrito na superfície imagética que gera significados sobre o tema.

Sousa (2004a) afirma que no fotojornalismo cinco forças agem simultânea e interativamente. São elas a ação pessoal, a ação social, a ação ideológica, a ação cultural e a ação tecnológica. Para o autor, as cinco contribuem para que o fotojornalismo evolua de uma determinada forma e não de outra, sendo o que é. "[...] Os fotojornalistas fotografam com as ideologias que trazem consigo." (SOUSA, 2004a, p. 226). Isso significa dizer que fotografar é um ato intencional no qual os repórteres fotográficos produzem imagens conscientes da informação que querem transmitir.

Porém, apesar de ser um ato intencional, até recentemente a fotografia não era analisada como tal. As análises fotográficas se limitavam às induções e deduções do analista (pesquisador) e não de seu produtor (fotógrafo). Com isso, as análises eram construídas a partir do produto final (fotografia), baseadas nas percepções de um terceiro, o pesquisador. Pela proposta metodológica da intencionalidade de comunicação, o analista continua sendo um terceiro, o pesquisador, mas, ao invés de partir do produto final (fotografia) para frente (induções e deduções do pesquisador), ele age em sentido inverso, do produto final para trás (fotógrafo), ou seja, trabalha com o percurso gerativo da fotografia, para identificar qual a intencionalidade de comunicação da mensagem fotográfica. 
Estudos em Jornalismo e Mídia - Vol. 9 № 2 - Julho e Dezembro de 2012

Para tanto, o pesquisador desconstrói a fotografia, analisando separadamente os recursos técnicos (sabendo, obviamente, que o uso de cada recurso provoca um efeito visual na imagem) e os elementos da linguagem fotográfica (conhecendo, naturalmente, que um ângulo pode "achatar" ou "supervalorizar" um elemento fotografado) utilizados para a composição fotográfica. Assim, por meio da soma dos resultados visuais provocados pelos recursos técnicos e dos conceitos e recomendações de uso dos elementos da linguagem fotográfica, o pesquisador pode identificar a (ou, no mínimo, se aproximar da) intencionalidade de comunicação do fotógrafo, quando do registro de uma imagem, ou do editor de fotografia um veículo de comunicação, quando de seu uso.

\section{Objeto e corpus do estudo}

O objeto deste estudo consiste nas fotografias sobre a crise na assistência à saúde pública no município de Londrina, tendo como recorte os meses de fevereiro e março de 2011. Neste período, os serviços de saúde apresentaram alto grau de comprometimento levando a população a enfrentar muitos problemas para ser atendida.

O cenário na saúde londrinense revela falta de profissionais na clínica básica (ginecologia, pediatria e clínica geral), com terceirização dos plantões nas unidades básicas; falta de plantonistas no Pronto Atendimento Municipal (Adulto e Infantil), gerando superlotação e demora do atendimento; sobrecarga nas atividades do Serviço de Atendimento Móvel de Urgência (Samu) e do Serviço Integrado de Atendimento ao Trauma e Emergência (Siate); e falta de leitos hospitalares gerais e de UTI.

Essa situação é consequência de medidas político-administrativas adotadas pelos gestores municipais do sistema. Pela legislação, os gestores municipais são o prefeito e o secretário municipal de saúde. O prefeito de Londrina, Homero Barbosa Neto, assumiu o comando da prefeitura em $1^{\circ}$ maio de 2009 , depois de um conturbado processo eleitoral, em que o vencedor das eleições em 2008 (Antonio Belinati) teve a candidatura impugnada pelo Tribunal Superior Eleitoral (TSE), com a realização de um “terceiro turno". De maio de 2009 a maio de 2011, a Secretaria de Saúde de Londrina teve cinco titulares.

O corpus deste trabalho é constituído de dez fotografias (Quadro 1) do jornal Folha de Londrina, sendo duas do repórter fotográfico Celso Pacheco: em 27 de fevereiro (uma capa e um Folha Especial, p. 9); três da repórter fotográfica Olga Leiria: em 22 de março (uma capa e duas Folha Cidades, p. 3); cinco do repórter fotográfíco 
Estudos em Jornalismo e Mídia - Vol. 9 № 2 - Julho e Dezembro de 2012

ISSNe 1984-6924

DOI: http://dx.doi.org/10.5007/1984-6924.2012v9n2 p506

Marcos Zanutto: três em 11 de março (uma capa e uma Folha Geral, p. 6) e três em 24 de março (uma capa e duas Folha Geral, p. 9). Cada uma dessas fotografias será reproduzida em tamanho maior, com melhor definição, e analisada individualmente, conforme a metodologia proposta pelos autores.

Quadro 1: Apresentação das fotografias que compõem o corpus do trabalho
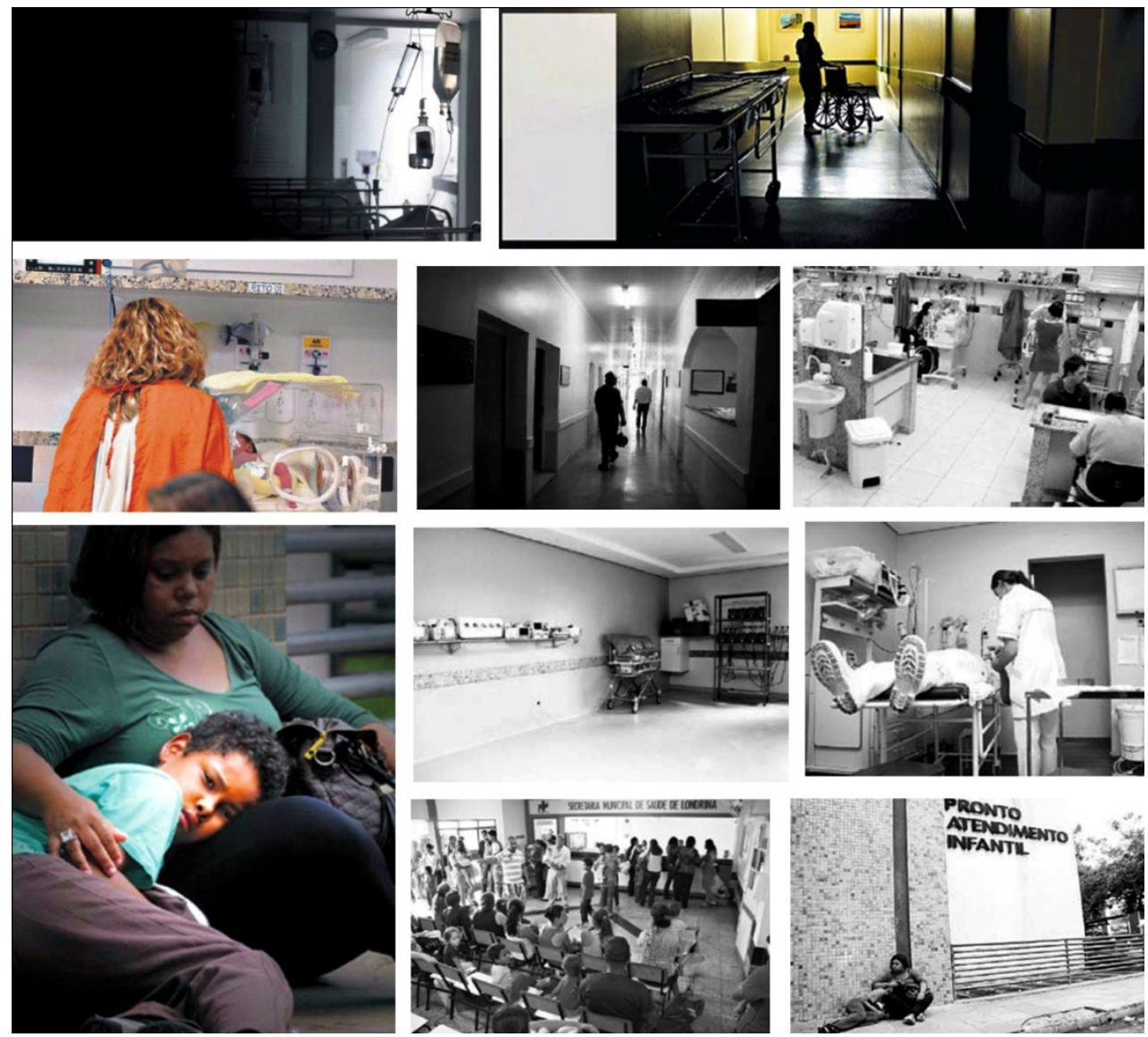

Quadro elaborado pelos autores

As referidas reportagens publicaram outras fotografias, mas foram desconsideradas por não apresentarem relação direta com a assistência à saúde, na relação profissional e paciente. São imagens de autoridades, profissionais e pacientes em formato boneco (pose) ou fachadas de prédios. As imagens selecionadas e analisadas são referentes ao processo de atendimento, equipamentos e ambientes hospitalares que mostram a assistência direta à saúde do paciente.

A Folha de Londrina, durante o período estudado, publicou reportagens com fotografias de problemas na saúde pública em municípios da região norte do Estado. Essas imagens também foram consideradas para efeito de análise porque Londrina é polo referencial para municípios da região, que não oferecem serviços de complexidade. Caso os serviços de Londrina sejam afetados por medidas político-administrativas locais 
Estudos em Jornalismo e Mídia - Vol. 9 № 2 - Julho e Dezembro de 2012

os municípios da região também são prejudicados porque, na regionalização da estrutura do Sistema Único de Saúde (SUS), Londrina é suporte para outras localidades.

\section{Fotografia: a intencionalidade do repórter fotográfico}

As figuras 1 e 2 são de autoria do repórter fotográfico Celso Pacheco e foram publicadas no dia 27 de fevereiro na capa e na página 9, respectivamente. A fotografia da figura 1 foi tomada em plano médio e apresenta uma relação equilibrada dos elementos fotografados. Apesar de a imagem não mostrar o componente humano, há uma riqueza de detalhes de objetos hospitalares: camas e equipos com frascos de soluções medicamentosas.

O foco está nesses objetos em primeiro plano e a composição obedece à regra dos terços já que esses elementos estão em pontos de ouro. Apesar de colorida, a imagem ostenta um tom monocromático realçado pelo jogo luz e contrastes, em que a iluminação presta-se a um papel fundamental: realçar objetos icônicos que remetem automaticamente ao ambiente hospitalar, portanto à assistência à saúde do paciente.

A iluminação oferece incontáveis possibilidades de expressão ao fotógrafo. O domínio da iluminação e sua utilização direcionada, em particular, permite ao fotógrafo enfatizar determinado elemento do cenário, destacando-o dos demais, valorizando-o em detrimento dos outros (BONI, 2003, p. 184).

A fotografia foi tratada digitalmente e escurecida da metade para a esquerda. Neste fundo preto, foram inseridos, em letras brancas, a manchete e o texto da chamada. Tradicionalmente, a cor preta está associada a coisas ruins, inclusive, na cultura ocidental, muitos países a usam em sinal de luto, ou seja, em respeito à morte.

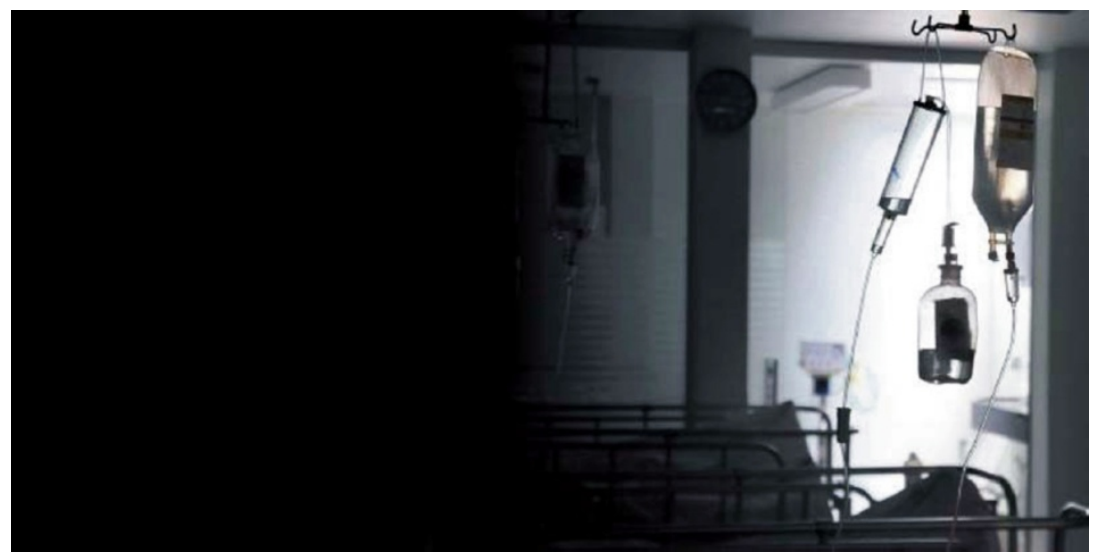

Figura 1 - "Falência múltipla - Paraná vive caos na saúde"

Fotografia: Celso Pacheco - Fonte: Folha de Londrina - capa - 27/02/2011 
Estudos em Jornalismo e Mídia - Vol. 9 № 2 - Julho e Dezembro de 2012

Essa impressão é corroborada pelo subtítulo da reportagem "Falência múltipla". Tecnicamente, o termo falência múltipla está associado à falência de vários órgãos vitais, causa que leva à morte do paciente. A reportagem, com esse subtítulo, atesta a falência do sistema público de saúde, realçado ainda pela manchete "Paraná vive caos na Saúde". O tom sombrio da fotografia remete a sensações de abandono da saúde pública, potencializado pela manchete da reportagem que destaca as palavras falência e caos. Pode-se afirmar que a produção desta fotografia tem essa intencionalidade, inclusive, por se tratar de uma edição dominical, espaço reservado a grandes reportagens, que precisam de maior planejamento tanto da pauta do texto quanto da pauta fotográfica.

A fotografia da figura 2 foi publicada em preto e branco; seu plano é o médio e a composição apresenta grande perspectiva por causa do corredor hospitalar. O componente humano está próximo aos pontos de ouro, na regra dos terços. Os dois homens caminham de costas para o repórter fotográfico que os registra sem identificálos, revelando uma preocupação de caráter ético.

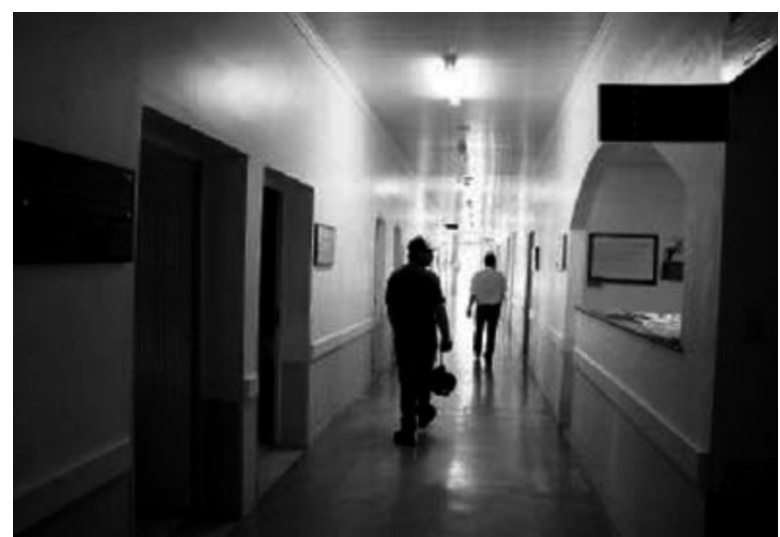

Figura 2 - "Na última década, pelo menos 100 instituições teriam fechado as portas" Fotografia: Celso Pacheco - Fonte: Folha de Londrina - p. 9 - 27/02/2011

Nesta imagem a iluminação exerce importante papel ao destacar o componente humano, quase ao centro da imagem, que caminha em direção a uma luz. Pode-se inferir que apesar da "luz ao fim do túnel”, o caos está instalado na saúde. A legenda ressalta que "na última década, pelo menos 100 instituições teriam fechado as portas". Nas duas fotografias, Celso Pacheco destaca elementos da linguagem fotográfica que revelam a sua intencionalidade em compor um cenário que retrate o caos da saúde pública.

A eleição de um aspecto determinado - isto é, selecionado do real, com seu respectivo tratamento estético -, a preocupação na organização visual dos detalhes que compõem o assunto, bem como a exploração dos recursos oferecidos pela tecnologia: todos são fatores que influenciarão decisivamente no resultado final e configuram a atuação do fotógrafo enquanto filtro cultural (KOSSOY, 2001, p. 42). 


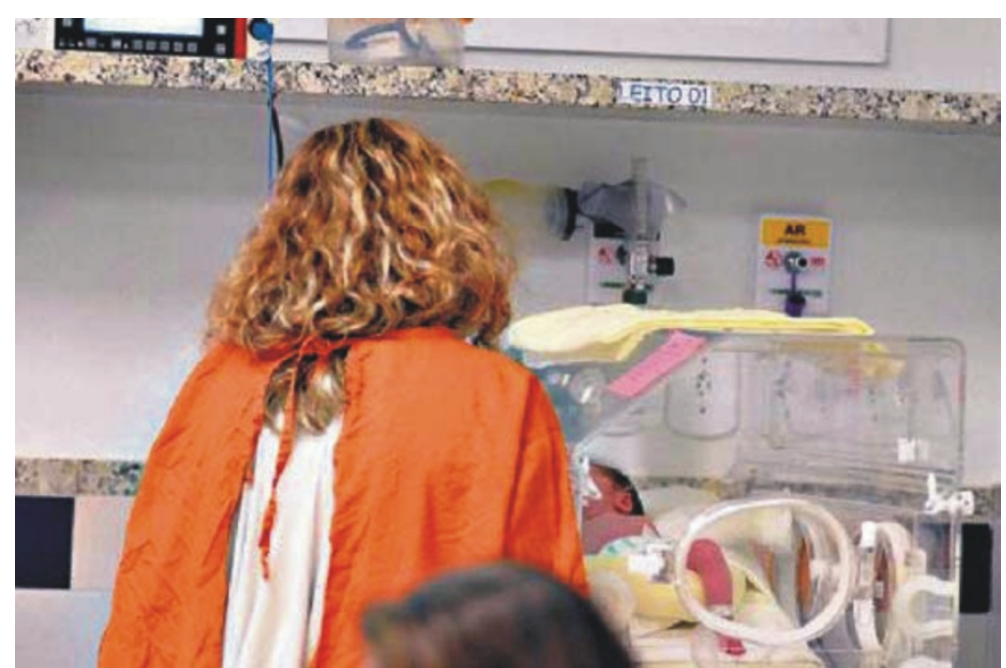

Figura 3 - "A Unidade de terapia Intensiva Neonatal e Pediátrica do Hospital Evangélico, de Londrina, foi interditada ontem por superlotação"

Fotografia: Marcos Zanutto - Fonte: Folha de Londrina - capa - 11/03/2011

As figuras 3 e 4 são de autoria do repórter fotográfico Marcos Zanutto. A primeira ilustra a chamada de capa do jornal e foi publicada em cores. A imagem foi tomada em plano fechado, valorizando elementos como um leito de Unidade de Terapia Intensiva (UTI) infantil, tendo um recém-nascido acompanhado por uma mulher, que se pressupõe ser sua mãe.

Essa imagem sozinha informa os cuidados médicos que o bebê recebe do hospital e o afeto proporcionado por sua mãe. No entanto, a fotografia precisa do texto para seu conteúdo imagético ser traduzido. É na contextualização que a fotografia informa e revela a intencionalidade do repórter fotográfico: "A Unidade de Terapia Intensiva Neonatal Pediátrica do Hospital Evangélico de Londrina, foi interditada ontem por superlotação."

A partir da leitura da primeira frase da chamada de capa fica claro que se trata da falta de leitos neonatais de UTI e que a unidade do Hospital Evangélico está superlotada. A sensação de superlotação fica mais evidente na figura 4. Nela são destacados quatro leitos ocupados, visto que em três há acompanhantes dos recémnascidos. Além disso, um casal conversa com uma profissional de saúde, que faz anotações, o que leva a pressupor que se trata de acompanhantes do recém-nascido do quarto leito, parcialmente visível, no canto superior esquerdo da fotografia. Os quatro leitos formam uma linha na parte superior da fotografia, dando movimento à imagem, da direita para a esquerda, em diagonal. 


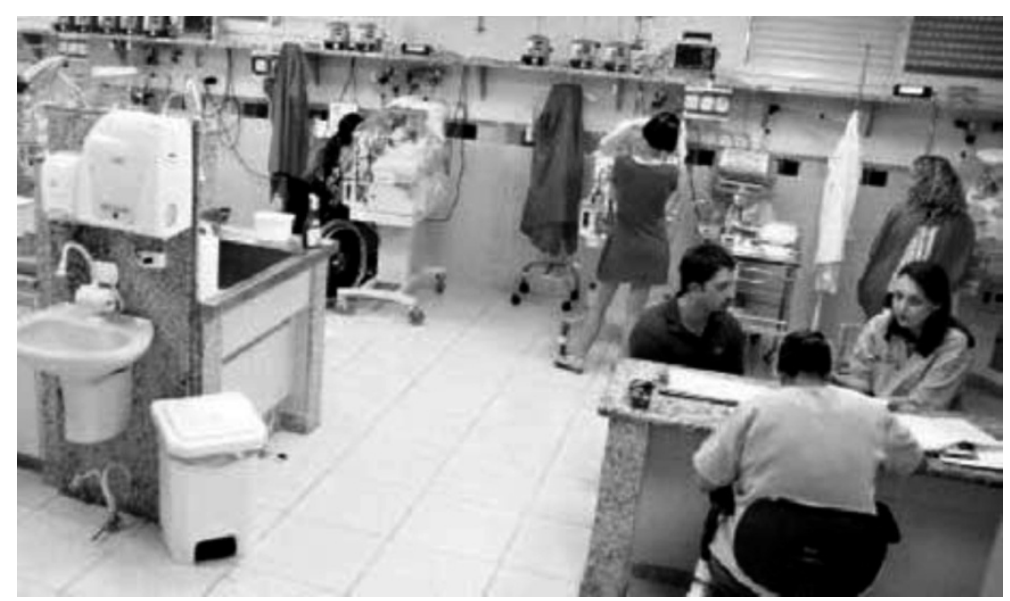

Figura 4 - "Superlotação motivou fechamento do setor"

Fotografia: Marcos Zanutto - Fonte: Folha de Londrina - p. 6 - 11/03/2011

As figuras 5, 6 e 7 são de autoria da repórter fotográfica Olga Leiria e foram publicadas no dia 22 de março. A imagem da figura 5 repete o recurso utilizado pelo jornal no dia 27 de fevereiro. Trata-se de uma imagem que ocupa a largura do jornal na cabeça de página, logo abaixo do logotipo da publicação. A fotografia foi tomada em plano geral, usado para fazer referência onde ocorre uma determinada ação, neste caso, o ambiente de um hospital.

A maca em primeiro plano está vazia no corredor e todo o primeiro plano da imagem surge numa penumbra, num efeito de iluminação que privilegia outros planos, dando grande efeito de perspectiva. A fotografia, tomada com iluminação insuficiente no primeiro plano, deve ter sofrido um trabalho de pós-produção para enfatizar ainda mais a parte escura, num processo de tratamento digital.

O tratamento digital não chega a manipular o seu conteúdo. Todavia, Sousa (2004b) afirma que a fotografia, como representação da realidade, sempre será uma forma de manipulação por causa de elementos como enquadramento, ângulo, objetos de composição, foco, profundidade de campo, ou seja, itens a serem escolhidos pelo fotógrafo no ato de produzir a imagem. Ele afirma que "o retoque, a alteração, a supressão, a inclusão de elementos nas imagens fotojornalísticas foram procedimentos relativamente comuns ao longo da história", mas adverte sobre questões éticas relacionadas a tal recurso.

Assim sendo, e apesar de as novas tecnologias trazerem vantagens incontestáveis no que respeita à qualidade da imagem, à expressividade e à capacidade de se vencer o tempo e espaço com rapidez e comunidade, as questões ligadas à geração e manipulação digital de imagens são, talvez, das mais relevantes para o fotojornalismo atual, especialmente no que diz respeito à ética e à deontologia profissionais (SOUSA, 2004b, p. 116). 
No centro da figura 5, uma profissional de saúde empurra uma cadeira de rodas também vazia. O componente humano ao centro aparece em silhueta por estar na contraluz. A maca e a cadeira de rodas vazias estão em consonância com o título da chamada de capa "Crise na saúde", que é aplicada sob a imagem numa caixa de texto com fundo branco. Essa crise impede que pacientes sejam atendidos e o instrumentário hospitalar permanece ocioso.

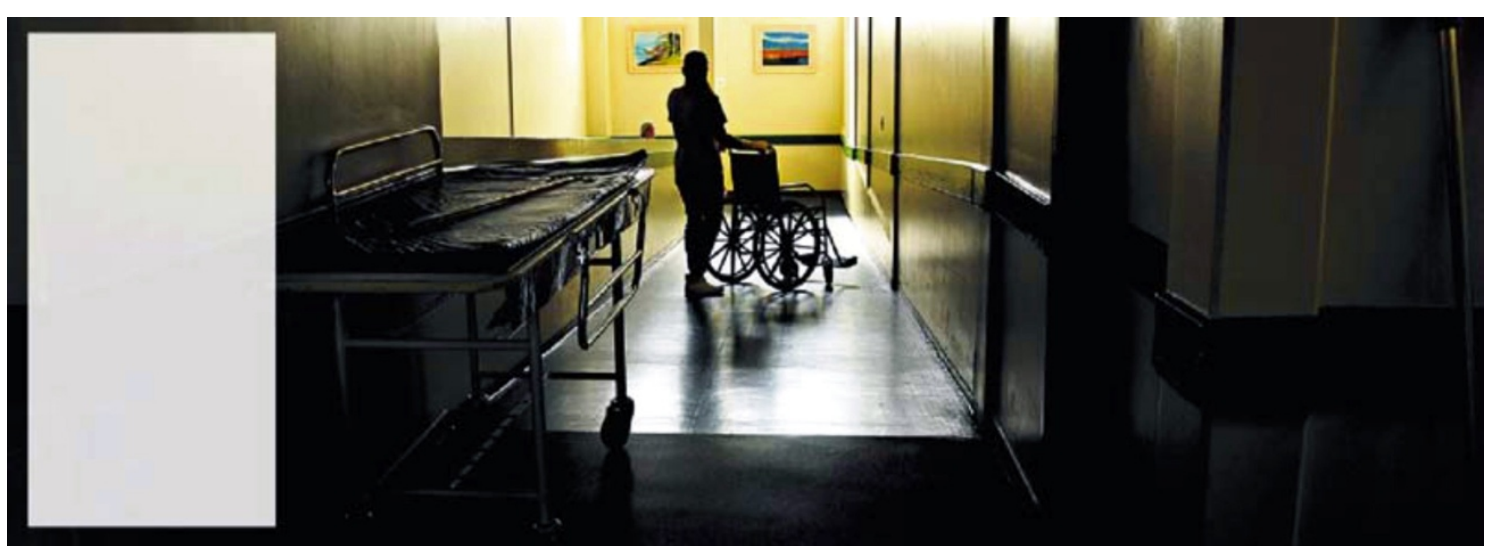

Figura 5 - "O Hospital São Rafael, de Rolândia (Norte), corre o risco de fechar" Fotografia: Olga Leiria - Fonte: Folha de Londrina - capa - 22/03/2011

É possível afirmar que a composição dessa imagem (Figura 5) é intencional por causa dos elementos referidos para conferir à reportagem a veracidade de crise, caos e falência, termos que aparecem de forma recorrente nas reportagens da Folha de Londrina para caracterizar o momento atual da saúde pública. Além disso, a profissional de saúde ao centro da fotografia está numa posição estática, os pés estão alinhados dando a impressão de estar parada, provavelmente num pedido feito pela repórter fotográfica para registrar a cena.

A relação crise (falta de atendimento) versus instrumentos ociosos volta a ser foco de outra fotografia de Olga Leiria (Figura 6). Nela a repórter fotográfica retrata a estrutura física de uma UTI no Hospital São Rafael, de Rolândia, mantido pela Irmandade Santa Casa de Londrina (Iscal). Em perspectiva e com profundidade de campo, Olga Leiria mostra leitos de UTI e outros equipamentos no canto de uma sala, esperando para entrar em funcionamento. A legenda atesta que a estrutura "para dez leitos, está pronta há um ano". 


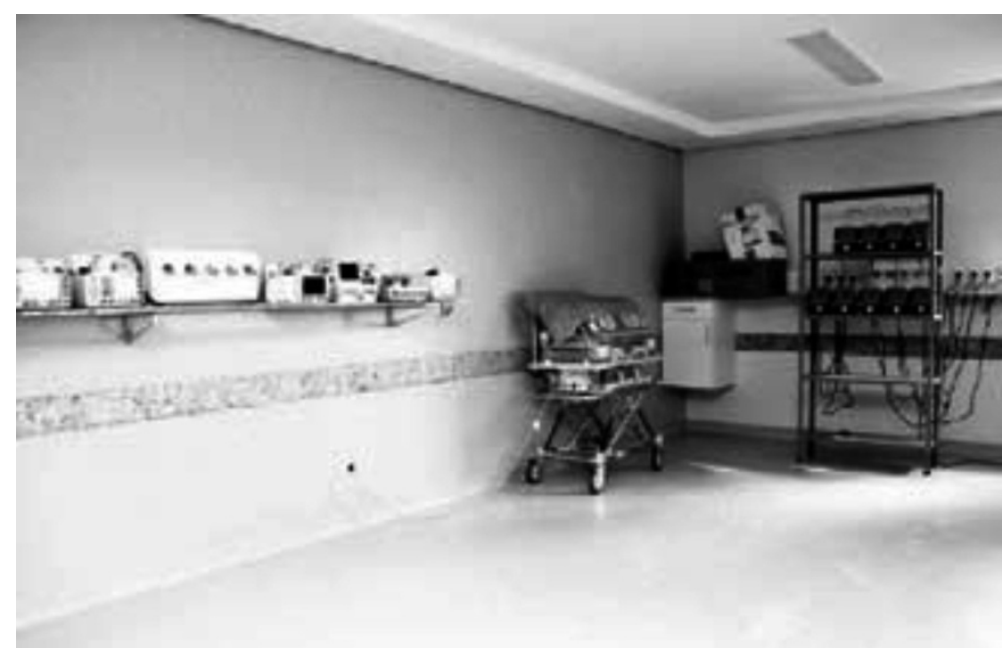

Figura 6 - "Estrutura física da UTI, com capacidade para dez leitos, está pronta há um ano" - Fotografia: Olga Leiria - Fonte: Folha de Londrina - p. 3 - 22/03/2011

Os equipamentos parados levam a um questionamento pertinente. Qual é a crise na saúde se há equipamentos novos sem uso? A resposta está exatamente no processo de construção de uma ala hospitalar. Os equipamentos são uma parte deste processo, visto que é necessário investir em recursos humanos para poder operá-los. Sem o componente humano, os equipamentos continuarão sem uso.

Essa constatação é reforçada numa associação com o conteúdo informativo da figura 7, na qual Olga Leiria retrata no mesmo hospital - São Rafael, em Rolândia - o atendimento a um trabalhador. Essa inferência encontra respaldo na vestimenta do paciente atendido: roupas e botas brancas, o que leva a pressupor que seja um operário da indústria da alimentação.

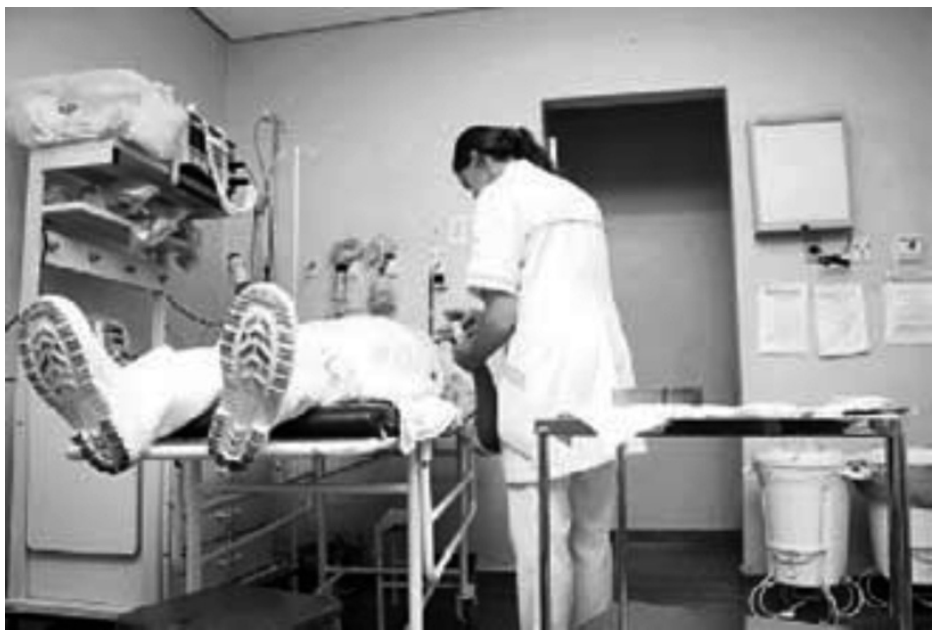

Figura 7 - "Hospital São Rafael: $80 \%$ dos atendimentos são de pacientes do SUS" Fotografia: Olga Leiria - Fonte: Folha de Londrina - Folha Cidades - pág. 3 -22/03/2011 
Estudos em Jornalismo e Mídia - Vol. 9 № 2 - Julho e Dezembro de 2012

As duas fotografias (Figuras 6 e 7) foram publicadas uma ao lado da outra e revelam nessa associação que não há mais atendimento aos usuários do SUS por não haver recursos e investimentos suficientes para a contração de pessoal.

A falta de atendimento ao usuário volta a ser tema de mais uma reportagem da Folha de Londrina no dia 24 de março, com fotografias de Marcos Zanutto (Figuras 8, 9 e 10). A imagem da figura 8, de capa em cores, mostra uma mãe sentada do lado de fora do Pronto Atendimento Infantil (PAI) que está superlotado. Essa informação pode ser lida numa associação com o texto de chamada da capa e também a partir das figuras 9 e 10 que identificam o PAI, serviço de pronto-atendimento da Secretaria de Saúde de Londrina.

A falta de atendimento é reforçada pela mãe com o filho no colo do lado de fora do PAI, na calçada, visto que o saguão de espera (Figura 9) está lotado. A manchete da reportagem à página 9 é explícita neste sentido: “Caos no PAI revolta usuários do SUS".

A imagem da figura 8 foi tomada na vertical com o uso de uma teleobjetiva, para não incomodar mãe e filho. O plano é fechado e o ângulo é normal (linear). O olhar do fotógrafo está na mesma altura do rosto do menino deitado sobre o colo da mãe, que tem uma sombra sob o seu rosto, recurso potencializado na pós-produção com software de edição de imagem. Esse recurso aumenta a sensação de dor pela demora no atendimento ao filho.

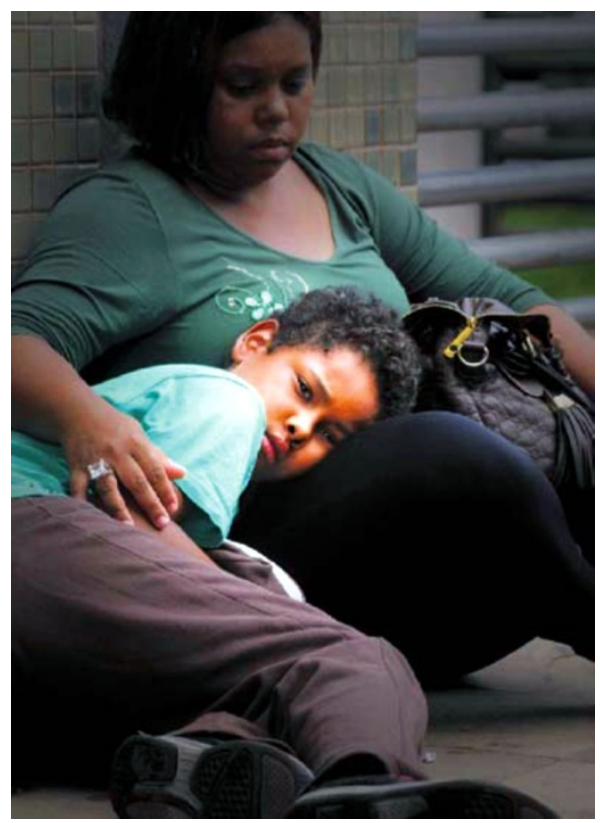

Figura 8 - "A espera no Pronto-Atendimento Infantil de Londrina, que chegou a 12 horas ontem, revoltou pais e responsáveis" Fotografia: Marcos Zanutto - Fonte: Folha de Londrina - capa - 24/03/2011 
Estudos em Jornalismo e Mídia - Vol. 9 № 2 - Julho e Dezembro de 2012

A fotografia (Figura 8) transmite sensação de abandono na saúde pública e a composição da mãe com o braço direito sobre o filho confere proteção e cuidado, o que não é conferido pelo serviço público de saúde.

A sensação de caos e abandono fica explícita numa associação das figuras 9 e 10, publicadas uma abaixo da outra. A superlotação no PAI é tamanha que mãe e filho esperam do lado de fora da unidade. A figura 10 é ainda mais representativa para o momento atual da saúde pública. Seu plano é o geral e a composição é bastante significativa. Na regra dos terços, a inscrição Pronto Atendimento Infantil aparece num ponto de ouro e na diagonal, noutro ponto de ouro, estão a mãe e o filho, os mesmos personagens da fotografia de capa.

A mãe olha para fora da imagem. Seu olhar vazio revela desesperança. Esse sentimento é corroborado por ela e o filho esperarem pelo atendimento sentados na calçada, situação de deterioração do serviço público de saúde. Deterioração que encontra respaldo inclusive com o meio-fio sem manutenção adequada que aparece no canto inferior direito da imagem.

Kossoy (2001, p. 43) afirma que a fotografia é o documento da atitude do próprio fotógrafo. "O registro visual documenta, por outro lado, a própria atitude do fotógrafo diante da realidade; seu estado de espírito e sua ideologia acabam transparecendo em suas imagens [...]."

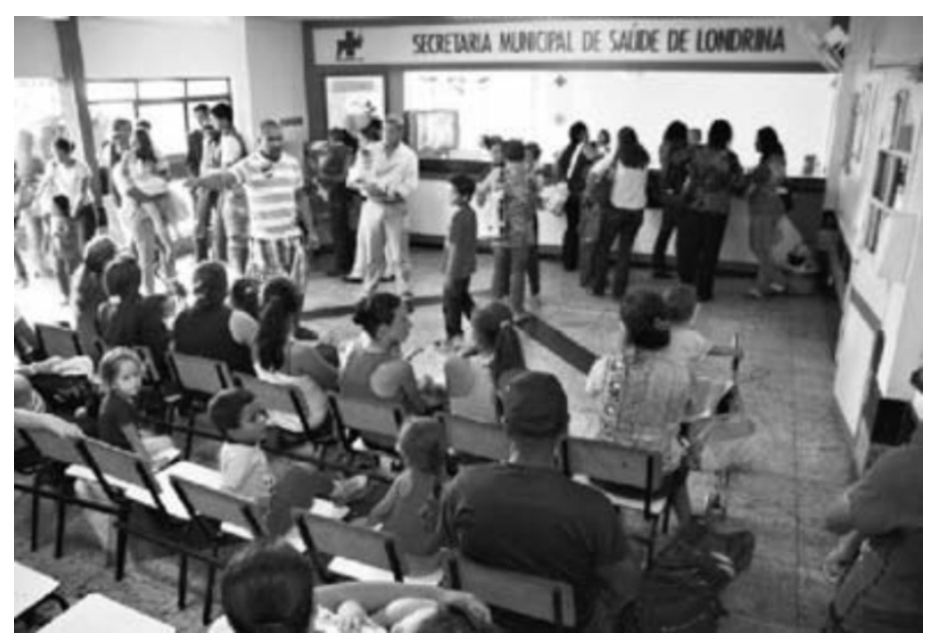

Figura 9 - "Passar horas na sala de espera lotada virou rotina para quem depende da saúde pública em Londrina"

Fotografia: Marcos Zanutto - Fonte: Folha de Londrina - pág. 9-24/03/2011 


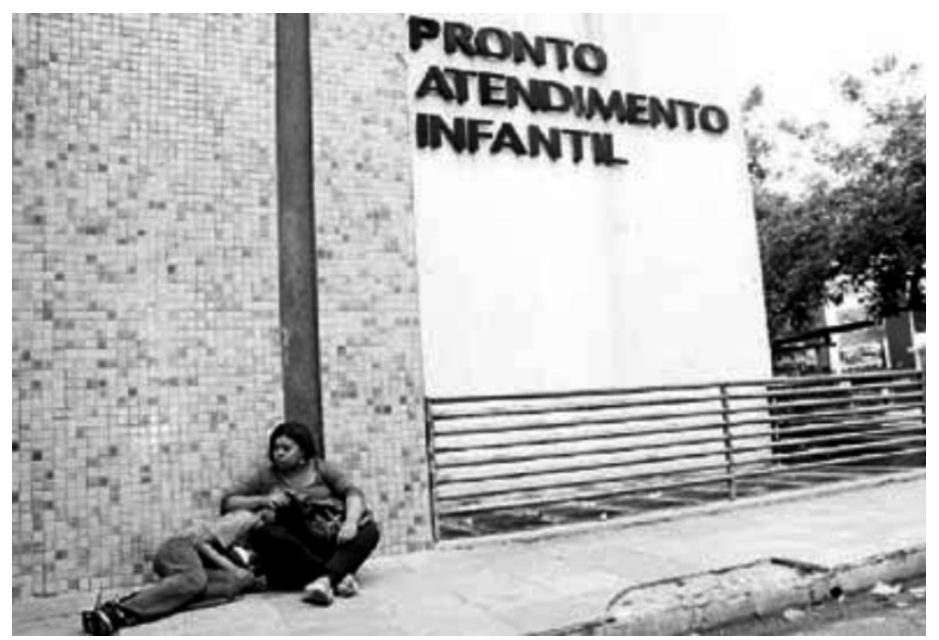

Figura 10 - "A faxineira Daniela Rocha passou o dia em busca de socorro para o filho com suspeita de dengue"

Fotografia: Marcos Zanutto - Fonte: Folha de Londrina - pág. 9 - 24/03/2011

Custódio (2006, p. 146) afirma que retratar a superlotação hospitalar é mostrar as dificuldades dos "pacientes em macas em um longo corredor. A imagem, que virou ícone e já se banalizou, de tão gasta, tem sido usada na imprensa escrita de Londrina há muitos anos". O autor afirma que paciente em maca é clichê e a superlotação é retratada com excesso de pacientes nos corredores representando o caos na saúde pública.

Esse estudo verificou que o caos é representado pelo excesso de pacientes em espera, corroborando as conclusões de Custódio (2006). Por outro lado, o mesmo caos também é representado pelo vazio, seja da maca, seja da cadeira de rodas, seja dos equipamentos ociosos. Isso fica evidenciado na figura 1 que não tem pacientes, apenas objetos icônicos do ambientes hospitalar; na 5 que ostenta maca e cadeira de rodas vazias; e na figura 6 cujo leito de UTI está desativado.

A noção de crise, falência e caos da saúde púbica pode ser construída imageticamente tanto pelo excesso de pacientes quanto pela falta deles, ou seja, o vazio de uma fotografia remete ao paciente que espera pelo atendimento, fora da imagem, às vezes numa sala superlotada ou numa calçada.

O caos nas fotografias como intencionalidade dos repórteres fotográficos corrobora com os problemas da área de saúde. As medidas político-administrativas de um governo, com a implantação ou desestruturação de programas assistenciais, podem levar ao caos no setor, ainda mais considerando que num período de dois anos, Londrina teve cinco titulares à frente da Secretaria Municipal de Saúde, uma média de 4,8 meses por secretário, ou seja, tempo insuficiente para consolidar mudanças que promovam efetivamente a qualidade na assistência à saúde da população. 


\section{Considerações finais}

Escolher um plano, determinar os objetos de cena de uma composição, estudar a iluminação, pontuar o foco dos elementos, dar profundidade de campo, conferir movimento e perspectiva são possibilidades da linguagem fotográfica que permitem ao repórter fotográfico escrever informações na superfície de uma imagem, ou seja, gerar sentidos, criar significados.

Essas possibilidades se dão a partir da visão pessoal do fotógrafo e os recursos tecnológicos que estão disponíveis, no que Flusser (2002, p. 31) classifica como as possibilidades do aparelho e seu programa. "Neste sentido, o aparelho funciona em função da intenção do fotógrafo. Mas sua 'escolha' é limitada pelo número de categorias inscritas no aparelho [...]."

Independente das possibilidades inscritas no aparelho, o fato é que o significado da fotografia é inscrito também a partir da intencionalidade de comunicação do profissional da fotografia que constrói um sentido e não outro, conforme a sua pauta fotográfica e, principalmente, de acordo com a sua visão sobre o assunto fotografado, permeado por valores pessoais, que vão de valores morais a princípios ideológicos.

A área da saúde pública ganha as páginas dos jornais, principalmente, quando o tema envolve fatos e acontecimentos que afetam a oferta de serviços à população. Os sintomas desses problemas são as fillas, a falta de médicos e a interrupção de programas e de atendimento aos usuários do SUS, provocando a indignação de quem precisa do serviço e resposta do gestor municipal.

Neste sentido, esse trabalho permite afirmar que há intencionalidade do repórter fotográfico, que constrói um sentido quando leva informação ao leitor e que a linguagem fotográfica é explorada para compor significados nas reportagens. As fotografias produzidas pelo jornal Folha de Londrina evidenciam a intencionalidade dos seus repórteres fotográficos que inscrevem informações significativas sob a superfície da imagem captada. Informações que dão significados que passam - no caso da saúde pública de Londrina (a partir do objeto de estudo deste trabalho) a noção de crise, a sensação de falência, enfim, o sentido de caos. 


\section{Referências Bibliográficas}

BONI, Paulo César. O discurso fotográfico: a intencionalidade de comunicação no fotojornalismo. São Paulo, 2000. Tese (Doutorado em Ciências da Comunicação) - Universidade de São Paulo, 2000.

Linguagem Fotográfica: objetividade e subjetividade na composição da mensagem fotográfica. Formas e Linguagens, Ijuí/RS, n.5, p.165-187, jan./jun. 2003.

CUSTÓDIO, José de Arimathéia Cordeiro. Eternas macas, eternas marcas. Discursos Fotográficos, Londrina, v.2, n.2, p.141-158, 2006.

FLUSSER, Vilém. Filosofia da caixa preta: ensaios para uma futura filosofia da fotografia. Rio de Janeiro: Relume Dumará, 2002.

KOSSOY, Boris. Fotografia e história. 2.ed. rev. São Paulo: Ateliê Editorial, 2001.

SOUSA, Jorge Pedro. Uma história crítica do fotojornalismo ocidental. Florianópolis: Letras Contemporâneas, 2004a.

Fotojornalismo: introdução à história, às técnicas e à linguagem da fotografia na imprensa. Florianópolis: Letras Contemporâneas, 2004b.

Este artigo e todo o conteúdo da Estudos em Jornalismo e Mídia estão disponíveis em http://www.periodicos.ufsc.br/index.php/jornalismo/index

Estudos em Jornalismo e Mídia está sob a Licença Creative Commons. 